\title{
Narrativa de violência sexual: caso do Centro de Atendimento Integrado 18 de Maio
}

\author{
Narrative of sexual violence: case of the Centro de Atendimento Integrado 18 de Maio
}

\author{
Clawdemy Feitosa e Silva* \\ Sidelmar Alves da Silva Kunz** \\ João Carlos Felix de Lima***
}

\section{Resumo:}

O objetivo deste trabalho é analisar as boas práticas humanizadas e recomendações para uma política pública de Estado, com recorte no Centro de Atendimento Integrado 18 de Maio, destinado ao atendimento de crianças e adolescentes vítimas de violências, instalado no Distrito Federal (Brasil), em 2016. Quais seriam as boas práticas no atendimento a essas crianças e adolescentes, vítimas de violência sexual, de modo a se tornarem recomendações de políticas públicas de Estado, com consequente ampliação de novos centros? Em termos metodológicos, os dados foram consolidados com base em revisão de literatura de publicações recentes da ONG Childhood, no período de 2014 a 2018; em estudos empíricos e ensaios teóricos publicados na literatura científica, enfatizando as peculiaridades da realidade institucional, social, cultural e econômica da Capital Federal. Na análise, são considerados os relatos e as ações de experiências dos sujeitos de direitos (crianças e adolescentes) frente às denúncias recebidas pelo Disque 100, no contexto da submissão da vítima (criança e adolescente) à reapresentação de narrativa de violência sexual e suas consequências para esses sujeitos. Aponta-se que as boas práticas fazem parte do processo de atendimento e são responsáveis pela qualidade do trabalho desempenhado pelos profissionais especializados. Aponta-se, ainda, que a falta de interação e promoção entre os demais órgãos da rede de proteção pode causar graves problemas na implementação de políticas públicas de Estado.

Palavras-chave: Violência sexual. Rede de Proteção. ECA.

\begin{abstract}
:
The objective of this paper is to analyze the humanized good practices and recommendations for a public policy of the State, with cut in the Centro de Atendimento Integrado 18 de Maio, aimed at the care of children and adolescents victims of violence, today, installed in the Federal District (Brazil), in 2016. What would be the best practices in the care of these children and adolescents, victims of sexual violence, in order to become recommendations of state public policies, with consequent expansion of new centers? In methodological terms, the data were consolidated based on a literature review of recent publications of the ONG Childhood, from 2014 to 2018, empirical studies and theoretical essays published in the scientific literature, emphasizing the peculiarities of the institutional, social, cultural and economic reality of Federal District. In the analysis, the reports and the actions of experiences of the rights subjects (children and adolescents) regarding the

\footnotetext{
* Professor do Instituto Superior de Ciências Policiais (ISCP/PMDF), orientador da Escola Nacional de Socioeducação (ENS/UnB) e avaliador do MEC. Mestre em Direitos Humanos (UnB).

** Pesquisador do Inep e doutorando em Educação pela Universidade de Brasília (UnB). Doutorando em Educação (UnB), mestre em Geografia (UnB), especialista em Ontologia e Epistemologia (Unyleya).

*** Professor e pesquisador do Instituto Superior de Ciências Policiais (ISCP). Doutor em Teoria e Crítica Literária, mestre em Literatura Brasileira e Graduado em Letras Português pela Universidade de Brasília (UnB).
} 
complaints received by Dial 100 are considered, in the context of the submission of the victim (child and adolescent) to the re-presentation of narrative of sexual violence and its consequences. for these guys. Good practices are part of the service process and are responsible for the quality of work performed by specialized professionals. It is also pointed out that the lack of interaction and promotion between the other organs of the safety net can cause serious problems in the implementation of state public policies.

Keywords: Sexual violence. Protection net. ECA.

\section{Introdução}

O abuso e a exploração sexual de crianças e adolescentes têm sido uma prática sociocultural recorrente em muitas nações e, lamentavelmente, o Brasil ainda não se desvencilhou dessa conduta de violência. Nessa perspectiva, este artigo apresenta uma análise documental do Centro 18 de maio, fundado em dezembro de 2016 em Brasília, depois de tratativas que se deram entre a ONG Childhood Brasil e o Governo do Distrito Federal, que se estenderam por aproximadamente 5 anos. A criação do Centro deu-se como resposta a uma demanda, originada pela leitura da chamada Lei da Escuta.

A Lei, normalmente denominada Lei da Escuta, promulgada em 2017, constitui-se como uma das normatizações mais recentes destinadas a criar mecanismos de prevenção e coibição à violência, além de estabelecer medidas de assistência e proteção à criança e ao adolescente em situação de violência. Essa norma está amparada nos termos do art. 227 da Constituição Federal de 1988, na Convenção sobre os Direitos da Criança e seus protocolos adicionais e na Resolução no 20/2005 do Conselho Econômico e Social das Nações Unidas.

No total, hoje, existem 6 unidades de atendimento no Brasil e 2 no exterior. 0 recorte subsidia apenas e, em especial, o único Centro de Atendimento Integrado 18 de maio (CAI 18 de maio) situado em Brasília (DF), em cumprimento à Lei da Escuta. Essa lei estabelece princípios para a escuta protegida e para o depoimento especial de crianças e adolescentes, vítimas de violências, com o escopo de evitar a revitimização.

O problema deste trabalho foi identificar porque as boas práticas do Centro de atendimento integral às vítimas de abuso e violência sexual em Brasília não têm sido suficientes para recomendação de políticas públicas (com a devida ampliação de novos Centros) de Estado diante da legislação em vigor? 
É fácil verificar que a violência se repercute randomicamente contra o desenvolvimento social, dado que sem um desenvolvimento humano pleno, especialmente em fases como a infância e a adolescência, nucleares no horizonte de crescimento do ser humano, os prejuízos para as políticas públicas podem ser irreparáveis. Tendo isso como horizonte, as políticas promovidas pelo poder público precisam assumir a doutrina da proteção integral como ponto norteador para assegurar o direito à vida e à sobrevivência, sem sofrer qualquer tipo de sofrimento, abuso ou negligência. $E$, em caso de ocorrências dessa natureza, a intervenção deve ser a contento e com a presteza e profissionalismo necessários.

A própria Organização das Nações Unidas (ONU), ao definir os dezessete Objetivos de Desenvolvimento Sustentável (ODS), ressaltou que, dentre as propostas, enfatiza-se que para a promoção de uma sociedade pacífica é preciso "[...] acabar com abuso, exploração, tráfico e todas as formas de violência e tortura contra crianças" (ONU, 2015).

Diante da vulnerabilidade a que a criança e o adolescente são expostos, tais como, o abandono social, a marginalização e o desrespeito aos direitos humanos, cabe não somente ao Estado, mas também à sociedade civil, promover e garantir políticas públicas básicas condizentes com a dignidade humana.

As inquietações que envolvem essas práticas de violência ainda permanecem sobre o corpo infantil, simplesmente por não se compreender, talvez quais sejam os sentimentos que perpassam a infância e a adolescência, ignorância que ainda reverbera em nos pensamentos? Ou será que a partir do (re)conhecimento de suas idades, haverá o devido respeito diante da vulnerabilidade social? Ou ainda, será que os, adultos, já não valorizam a real dimensão do direito à infância e à adolescência?

O fato é que a violência que afeta as crianças e os adolescentes exige que se pense ações para o seu combate. Em face à defesa do estado da vítima, Furniss (1993, p. 35) afirma que inconscientemente a vítima procura apoiar-se em seus "[...] estados alterados de consciência para desligar-se da dor ou para dissociar-se de seu corpo". Em razão disso, legalmente, quando uma criança é vítima de violência, o agente investido pelo Estado deve recorrer ao depoimento da vítima, em alguns casos, por diversas vezes, no que se constitui como uma postura que pode implicar na ampliação da experiência traumática, o que agrava ainda mais aquele ato originário de violência. 
A ONG Childhood Brasil afirma que, atualmente, independentemente das questões de gênero e até mesmo de questões sociais, as crianças "vítimas de violências são ouvidas, em média, oito vezes" (MEDEIROS, 2014, p. 228), ao longo de um processo judicial, precisando repetir - e, importante mencionar, reviver - a situação de violência sofrida para diversos órgãos de atendimento, investigação e responsabilização (GONÇALVES; MAGALHÃES; SANTOS, 2017).

Na visão de Minayo (2010) e Oliveira (2013), a metodologia apresenta-se como o caminho da reflexão e da ação diante da realidade. Portanto, possibilita a compreensão por intermédio da articulação de métodos e técnicas para instruir, explorar e entender, bem como produzir novos conhecimentos. O presente estudo adotou abordagem qualitativa, pautada em análise documental, dentre outras fontes, das publicações recentes da ONG Childhood, no período de 2014 a 2018.

As reflexões se sustentam no diálogo com os referenciais teóricos, resultantes de pesquisa bibliográfica, atinentes ao objeto de investigação, com foco na delimitação dos aspectos conceituais e seus desdobramentos na política pública relacionada à defesa dos direitos humanos das crianças e dos adolescentes. O recorte refere-se às peculiaridades da realidade institucional, social, cultural e econômica da Capital Federal. As análises consideraram as ações e os relatos de experiências para com os sujeitos de direitos (crianças e adolescentes) frente às denúncias recebidas pelo Disque 100 , no contexto da submissão das vítimas à reapresentação de narrativa de violência sexual e as consequências para esses sujeitos.

A sociedade ainda perpetua condutas histórico-sociais no espaço-tempo de uma estrutura manipuladora e hierarquizada. E, parece não querer mudanças de posturas, pois muitos ainda consideram o corpo infantil como objeto, controle e alvo de poder. Não se está a produzir "soldados" ou "escravos" de épocas em que o corpo do outro era analisável e manipulável. E, onde se permite fazer o que se deseja e opere o que se determina, ou seja, perpetuar micropoderes sociais, perpassando todo o corpo social sem as reais transformações e modificações que se espera de uma conduta de cada cidadão para o seu pleno desenvolvimento humano (FOUCAULT, 2013).

Deve-se compreender que "[...] a representação que cada sociedade atribui à criança reflete à importância social dada ao corpo ao se desprezá-lo, ao se cultuá-lo ou ao se manipulá-Io" (FONSECA NETO; PAULA; BORGES, 2017, p. 139), logo, cabe à mesma 
sociedade ressignificar a real importância social que deve ser considerada em vista da criança e do adolescente, portadores de direitos.

Em pleno século XXI, tempo de evolução das tecnologias e das informações até mesmo do corpo, a sociedade parece encontrar-se permeada de contradições em pensar a criança como elemento da sociedade. Ainda está na memória coletiva o brutal assassinato de uma criança chamada Araceli, em 18 de maio de $1973^{1}$ em Vitória (ES), o qual somente quase 30 anos depois, veio a se transformar no aporte ao dia nacional de combate ao abuso e à exploração de crianças e adolescentes. A menina foi sequestrada, violentada e carbonizada por seus algozes.

Tendo em vista saber qual a contribuição do Centro de Atendimento Integrado 18 de Maio para o avanço na melhoria do atendimento e da escuta de crianças e adolescentes vítimas de violência sexual, este artigo buscou atender a dois propósitos específicos. O primeiro é o de apresentar as violações pétreas dos sujeitos de direitos a partir da Constituição federal de 1988 e a do Estatuto da Criança e do Adolescente, marcos para a proteção integral da criança e do adolescente, expondo um breve aporte conceitual desses sujeitos no processo de desenvolvimento humano. O segundo visa apresentar o Centro de Atendimento Integrado 18 de maio com suas boas práticas no atendimento e escuta das vítimas, ou testemunhas, do abuso e violência sexual e assim contribuir para que haja de forma efetiva uma ampliação dos Centros de Atendimento, não somente no DF, mas em todo o Brasil.

\section{Da Carta Magna de 1988 ao Estatuto da Criança e do Adolescente de 1990: as violações pétreas dos sujeitos de direitos}

A CF de 1988, após a redemocratização brasileira, possibilitou um marco para a perspectiva democrática de direito, após 21 anos de ditadura empresarial-militar, ou como prefere o Ministro Dias Toffoli, o Movimento de 1964. Convém perceber que os seus constituintes procuraram estabelecer importantes condições de salvaguarda dos sujeitos. A Constituição Federal assim preconiza:

\footnotetext{
${ }^{1}$ O Centro de Atendimento Integral 18 de maio possui essa data em homenagem ao caso Araceli, ocorrido em 1973.
} 
Art. 227. É dever da família, da sociedade e do Estado assegurar à criança, ao adolescente e ao jovem, com absoluta prioridade, o direito à vida, à saúde, à alimentação, à educação, ao lazer, à profissionalização, à cultura, à dignidade, ao respeito, à liberdade e à convivência familiar e comunitária, além de colocálos a salvo de toda forma de negligência, discriminação, exploração, violência, crueldade e opressão (BRASIL, 1988).

Sendo assim, cabe a todos, cidadãos, inculcar, promover e assegurar a dignidade da pessoa humana, independentemente, das fases de vida. No entanto, somente a CF 88 não foi suficiente para legitimar o direito da criança e do adolescente, foi preciso que o contexto sociopolítico e o texto da Convenção Internacional sobre os Direitos da Criança, por intermédio de organizações internacionais, impulsionassem os seus países membros para a assunção de postura mais incisiva na garantia e proteção integral aos direitos das crianças e dos adolescentes.

Em 13 de julho de 1990, sob o Governo de Fernando Collor, foi promulgado o Estatuto da Criança e do Adolescente (ECA). Em discurso no Congresso Nacional, foi enfatizada a preocupação de seu governo com a qualidade de vida das crianças:

Temos o dever de reverter essa situação; de garantir alimentação e saúde para as nossas crianças. Temos de tirá-las das ruas e dos desvios da marginalidade; de encaminhá-las à escola motivando-as para o estudo. Temos de levá-las de volta ao seio da família, ao convívio e guarda de pais capazes de dar-lhes sustento, afeto e amor; de fazer prevalecer o sentido da paternidade responsável. Temos de recuperar de uma vez por todas a família brasileira (COLLOR, 1990, p. 16).

O fato de o presidente ter proclamado dever de todos, assim como do Estado, sociedade e família; não significou uma concretização da lei sancionada, haja vista que até os dias correntes são encontradas diversas dificuldades para a aceitação e a implementação no corpo social das regras que norteiam a aplicação correta do ECA. Notase que o discurso aborda a necessidade de uma recuperação da família, entretanto, as questões em torno da família ainda padecem de grandes alterações para que os direitos da criança e dos adolescentes sejam assegurados. Pontua-se que o ECA é um marco para a proteção integral desses sujeitos de direitos, dado que define, no artigo 3o, que:

A criança e o adolescente gozam de todos os direitos fundamentais inerentes à pessoa humana, sem prejuízo da proteção integral de que trata esta Lei, assegurando-se-lhes, por lei ou por outros meios, todas as oportunidades e facilidades, a fim de lhes facultar o desenvolvimento físico, mental, moral, espiritual e social, em condições de liberdade e de dignidade (BRASIL, 1990). 
Parece que todos os direitos pétreos não contemplam a todas as crianças e adolescentes, logo, torna-se equidistante sua condição de cidadania, pois há "[...] uma parcela significativa das crianças brasileiras em situação de extrema violência social e física, assim como de pobreza" (FONSECA NETO; PAULA; BORGES, 2017, p. 151), de modo que muitas crianças e adolescentes ainda permaneçam na marginalização, sem a devida assistência e proteção.

Talvez o anseio de muitos seja em ajustar as crianças ao mundo dos adultos, postas na objetividade do mundo liberal de submissão e disciplina, mas continua-se a esquecer da sua subjetividade. Não atentam para o seu mundo, para sua percepção, sua interpretação, seus sentidos, sua aspiração, seu relacionamento de indivíduo com o mundo adulto, pelo contrário, marca-se a infância pela tensão desse ajustamento contraditório.

Ter o direito à vida encontra-se além da invenção do termo infância (ARIÈS, 1981), terminologia idealizada pelas sociedades modernas. Em vista desta infância, a sociedade deveria promover a plenitude de seus direitos socioculturais.

A criança ao nascer e ser acolhida no seio familiar explora o mundo simbólico e a linguagem da cultura social. Durante as interações pelas quais são submetidas no seu cotidiano, o seu corpo infantil vislumbra um mundo ideal de não violência, de um direito à sua própria infância, “[...] portanto, o brincar oferece à criança condições de se desenvolver e se apropriar de elementos da realidade por meio da compreensão dos seus significados" (GARANHANI; NADOLNY, 2011, p. 65).

No tocante à infância, ela deve ser entendida como uma etapa natural da vida dos indivíduos na proteção e promoção para o desenvolvimento pleno do corpo e não "[...] como algo que vai sendo montado, criado a partir de novas formas de falar e sentir dos adultos em relação ao que fazer com as crianças" (GHIRALDELLI JR., 2000, p. 49).

Quais seriam os desafios desses seres humanos em que as modificações sofridas durante o percurso natural da vida apresentam certos modelos nem tão aceitos pela mesma sociedade que os acolheu? Para Papalia e Feldman (2013, p. 37) “[...] o campo do desenvolvimento humano concentra-se no estudo científico dos processos sistemáticos de mudança e estabilidade que ocorrem nas pessoas e que dura a vida toda". Isto em se pensando em seus aportes físicos (do corpo e do cérebro), cognitivos (mudanças nas 
habilidades mentais) e psicossociais (mudança nas emoções, personalidade e relações sociais).

E quanto à adolescência? Possui a mesma proteção social? No entendimento de Alves et al. (2009, p. 72) “[...] a adolescência é uma fase de desenvolvimento constituída, como todas as outras, por questões socioculturais", portanto, na busca de sua identidade (pessoal, sexual, e ocupacional), Silva (2017, p. 67) assinala que “[...] ser adolescente é aflorar suas inquietações, é desafiar o mundo em sua plenitude e nas diversas formas". Mais: "a adolescência é uma construção social, uma transição no desenvolvimento que envolve mudanças físicas, cognitivas, emocionais e sociais, bem como assume formas variadas em diferentes contextos sociais, culturais e econômicos" (PAPALIA; FELDMAN, 2013, p. 386). Em função dessa condição, o adolescente não está imune à violência, à marginalização, ao preconceito, ao estresse, aos riscos de suas atitudes e aos deveres estabelecidos no ordenamento jurídico, assim como no pacto social.

Diante da violência a que as crianças e os adolescentes são expostos, há o reflexo direto em seu direito à saúde, que o próprio Ministério da Saúde no Brasil apresenta. O Ministério da Saúde (MS) tem divulgado dados acerca da violência que atinge crianças e adolescentes. De 2011 a 2017, foram apresentados dados em uma análise epidemiológica da violência sexual contra crianças e adolescentes, sistematizados logo abaixo, naquilo que se considera um grave problema de saúde pública, bem como, violação dos direitos humanos.

De acordo com o método da Organização Mundial da Saúde (OMS), o perfil epidemiológico ficou delimitado, considerando-se crianças aquelas na faixa etária entre zero e nove anos, e como adolescentes, entre dez e dezenove anos. Assinala-se que o MS adotou essa orientação mesmo em divergência àquilo que preconiza o ECA, o qual define criança aquelas com faixa etária até os 12 anos incompletos e adolescentes dos doze aos dezoito anos.

De acordo com o entendimento do MS acerca de violência sexual (tipificada como assédio, estupro, pornografia infantil e exploração sexual) são manifestações características os seguintes comportamentos: a) abuso incestuoso, b) sexo forçado no casamento, c) jogos sexuais e práticas eróticas não consentidas, d) pedofilia, e) voyeurismo, f) manuseio, g) penetração oral, anal ou genital, com pênis ou objetos, de forma forçada, h) exposição coercitiva/ constrangedora e atos libidinosos, i) exibicionismo, 
j) masturbação, k) linguagem erótica, I) interações sexuais de qualquer tipo e m) material pornográfico (BRASIL, 2018).

No período de 2011 a 2017, foram notificados no Sinan² 1.460 .326 casos de violência interpessoal ou autoprovocada. Desse total, foram registradas 219.717 (15,0\%) notificações contra crianças e 372.014 (25,5\%) contra adolescentes, concentrando 40,5\% dos casos notificados nesses dois cursos de vida. Nesse período, foram notificados 184.524 casos de violência sexual, sendo 58.037 (31,5\%) contra crianças e 83.068 (45,0\%) contra adolescentes, concentrando $76,5 \%$ dos casos notificados nesses dois cursos de vida. Comparando-se os anos de 2011 e 2017, observa-se um aumento geral de 83,0\% das notificações de violências sexuais e um aumento de $64,6 \%$ e $83,2 \%$ das notificações de violência sexual contra crianças e adolescentes, respectivamente (BRASIL, 2018).

O perfil das notificações de violência sexual contra crianças apresenta dados alarmantes, em que, na avaliação das características sociodemográficas de crianças vítimas de violência sexual, mostrou-se que 43.034 (74,2\%) eram do sexo feminino e $14.996(25,8 \%)$ eram do sexo masculino. Do total, 51,2\% estavam na faixa etária entre 1 e 5 anos, 45,5\% eram da raça/cor da pele negra, e 3,3\% possuíam alguma deficiência ou transtorno. As notificações se concentraram nas regiões Sudeste $(40,4 \%)$, Sul $(21,7 \%)$ e Norte (15,7\%) (BRASIL, 2018).

Outro dado alarmante é que na avaliação das características da violência sexual contra crianças mostrou-se que 33,7\% dos eventos tiveram caráter de repetição, 69,2\% ocorreram na residência; $4,6 \%$ ocorreram na escola; $62,0 \%$ foram notificados como estupro. Concomitantemente a tais violações à dignidade da pessoa humana, os dados apresentam as características do provável autor da violência sexual contra crianças. Neste caso, em $74,7 \%$ das notificações houve envolvimento de um autor. Em 81,6\%, o agressor era do sexo masculino e 37,0\% tinham vínculo familiar com a vítima (BRASIL, 2018). Por isso, é importante ressaltar que a luta para combater todo tipo de violência contra as crianças e os adolescentes deve ser realizada não somente em campanhas (datas sociais), mas também pelas redes de proteção, nas quais se inclui o Sistema Único de Saúde (SUS)

\footnotetext{
2 "O Sistema de Informação de Agravos de Notificação - Sinan é alimentado, principalmente, pela notificação e investigação de casos de doenças e agravos que constam da lista nacional de doenças de notificação compulsória (Portaria de Consolidação no 4, de 28 de Setembro de 2017, anexo V - Capítulo I) [...]. É, portanto, um instrumento relevante para auxiliar o planejamento da saúde, definir prioridades de intervenção, além de permitir que seja avaliado o impacto das intervenções." (SINAN, 2019).
} 
que também tem um papel importante na prevenção e enfrentamento à violência e na atenção integral às pessoas que vivenciaram a situação de violência.

O próprio MS reconhece que:

[...] a violência tem consequências profundas para a saúde física e mental nas pessoas que a vivenciam, tendo impacto no desenvolvimento psicossocial das crianças e adolescentes, no bem-estar das famílias e das comunidades, constituindo-se em desafios para os gestores e profissionais da saúde (BRASIL, 2018, p. 10).

\section{O processo de recontagem e submissão a (outra) violência}

A submissão à recontagem do ocorrido pode ser ilustrada na hipótese de submissão analítica de ocorrência policial apresentada à reapresentação de narrativa de violência sexual, onde, ocorrido um crime, a vítima é encaminhada a um agente de segurança pública que faz a escuta do relato da vítima concernente ao fato acontecido. Quase sempre, após isso, esse agente faz o encaminhamento e o transporte para o hospital, lugar em que a vítima fará novamente a narração do fato. Cumprida essa etapa, será feita a condução para a Delegacia da Polícia Judiciária (Civil), onde será feita, mais uma vez, a narração para o agente.

Finalizado esse momento, a vítima será direcionada à autoridade policial competente que preside inquéritos desta natureza. Na presença dessa autoridade policial, descreverá novamente o fato. Posteriormente, a vítima será intimada para comparecer ao Judiciário, momento em que relatará o acontecido, em momentos distintos, para pelo menos três atores importantes no Processo, indispensáveis, diga-se, ou seja, o promotor, o Juiz e o defensor público. Por fim, a vítima é destinada para acompanhamento com psicólogo que, como nas demais situações, solicitará à vítima a explicitação de todo o fato ocorrido.

Nessa situação hipotética analítica descrita, foram pelo menos oito narrativas, e, nesse contexto, fica evidente que, segundo esclarece Romaro e Capitão (2007, p. 151),

[...] a maioria dos pesquisadores concorda que o abuso sexual infantil é facilitador para o aparecimento de psicopatologias graves, prejudicando a evolução psicológica, afetiva e social da vítima. Os efeitos do abuso na infância podem se manifestar de várias maneiras, em qualquer idade da vida. 
Dado o exposto, há uma nova possibilidade, estabelecida por lei, para que não haja a revitimização, (o que acontece em pelo menos duas formas distintas de ouvir crianças e adolescentes), o que ainda não tem sido amplamente discutido para implementação de uma política pública de Estado.

Para modificar essa situação, há alternativas que se mostram mais saudáveis. Uma delas é a escuta especializada, realizada pelos órgãos da rede de proteção, de cunho estritamente necessário para o cumprimento de sua finalidade; a outra é o depoimento especial, realizado por autoridades policiais e judiciárias (Polícia Civil, Ministério Público, Defensoria Pública e Juizados da Infância ou criminais).

Diante do quadro de atendimento, existem, no exterior, 2 centros de atendimento. No Brasil, com seus 26 Estados e mais o Distrito Federal, têm-se apenas 6 centros de atendimento especializado, que são: Centro de Referência ao Atendimento Infanto-juvenil (CRAI), de Porto Alegre (RS); Pro Paz Integrado Criança e Adolescente, do Pará; Bem Me Quer Terê, de Teresópolis (RJ); Centro de Atendimento ao Adolescente e à Criança (CAAC), do Rio de Janeiro (RJ); Centro Integrado dos Direitos da Criança e do Adolescente, de Vitória da Conquista (BA); e Centro de Atendimento Integrado 18 de Maio, de Brasília (DF).

Nesse sentido, considerou-se que o Centro de Atendimento Integral 18 de maio situado no DF, tem sua peculiaridade por ser único da capital (mas poderia ter em outras regiões administrativas), e por estar na região central de Brasília (lugar em que são estabelecidas as políticas públicas nacionais) de forma (in)visível para o devido atendimento. $\mathrm{O}$ espaço construído possui vidraças espelhadas dificultando a visibilidade, e assim procura promover e resguardar a segurança das vítimas e testemunhas de violência e abuso sexual.

\section{Centro de Atendimento Integrado 18 de maio: as boas práticas}

Faz-se o recorte do único Centro de Atendimento Integrado, 18 de maio, localizado na área central da Capital da República. Este Centro tem a responsabilidade abstrata de atender as 31 regiões administrativas do Distrito Federal, tanto no que se refere às denúncias atendidas pelo Disque 100, quanto pelo encaminhamento dos Conselhos Tutelares. 
Segundo Gonçalves, Magalhães e Santos (2017), na apresentação do escopo proposto por todos os Centros, existe a premissa de atendimento, integração, proteção às vítimas de violência (abuso e exploração sexual) concentrando o provimento do Sistema de Garantia de Direitos de atenção em um mesmo espaço físico, de modo que esteja articulado com os demais órgãos da rede de proteção.

Cabe ressaltar que com o advento da Lei 13.431/2017 (BRASIL, 2017), o ECA fortaleceu-se ainda mais, pois a Lei da escuta, como é comumente conhecida, assegura que o atendimento às vítimas seja feito de forma protegida e não revitimizante. Também estabelece diretrizes para a integração das políticas públicas de atenção e proteção, mediante a implantação de centros integrados de atendimento, mas que, lamentavelmente, só existem 6 Unidades de atendimento no Brasil e 2 no exterior, um nos Estados Unidos da América (EUA) e o outro na Suécia, com estruturas diferentes, centros esses fundados por diversas questões culturais e estruturais (GONÇALVES; MAGALHÃES; SANTOS, 2017).

Importante destacar que, conforme dados do censo do Instituto Brasileiro de Geografia e Estatística (IBGE) de 2010, Brasília tinha uma população de 2,5 milhões de habitantes, sendo que $30 \%$ dessa população eram compostos por crianças e adolescentes.

Em 2011, a cidade de Brasília estava em primeiro lugar no ranking de denúncias de violências, conforme dados do Disque 100. Um longo processo de implementação desencadeou-se através de debates institucionais públicos e privados, além de tratativas de Grupos de Trabalhos. Nesse período, a democracia brasileira era dirigida pela primeira vez pelas mãos de uma mulher, a então presidente da República, Dilma Rousseff. Em seu primeiro mandato, ela declarou que o país estava unido, e, em especial, unido contra qualquer tipo de violência.

Em Brasília, o então Governador eleito do Distrito Federal, Agnelo Queiroz, filiado ao mesmo partido da então presidente, encontrou apoio para a implementação de políticas públicas sobre a pasta de segurança pública, até porque a capital federal encontrava-se num processo de crescimento populacional vertiginoso, ocupando no mesmo ano o 4일 lugar no ranking, segundo o Instituto Brasileiro de Geografia e Estatística - IBGE.

A ONG Childhood Brasil, em parceria com o Conselho Nacional de Justiça (CNJ), durante o I Encontro Nacional de Tomada de Experiências de Especial no Judiciário 
Brasileiro, foi ativa, a ponto de mediar junto ao National Children's Advocacy Center (NCAC) do Alabama, Estados Unidos, e com a Secretaria de Estado de Políticas para Crianças e Adolescentes, que na época era chamada de Secretaria da Criança, para apresentação da proposta do NCAC de treinamento para profissionais no atendimento às crianças e adolescentes vítimas de violência.

Ainda em 2011, o evento promovido na Secretaria de Direitos Humanos da Presidência da República (hoje Ministério dos Direitos Humanos), com o apoio das Instituições Públicas como Ministério Público (Coordenação da Infância e Juventude) e da Vara da Infância e Juventude e Instituições privadas (relacionadas à temática de atendimento às crianças e adolescentes, vítimas ou testemunhas de violências), promoveram ações conjuntas resultando na formação de um Grupo de Trabalho (GT) informal para a criação de um centro de atendimento integrado no DF.

As tratativas do GT foram realizadas na sede da Vara da Infância e Juventude do Tribunal de Justiça do Distrito Federal e Territórios (TJDFT), e demais órgãos dos poderes Judiciário e Executivo,além da Universidade Católica de Brasília (GONÇALVES; MAGALHÃES; SANTOS, 2017).

Somente em julho de 2013, o governo do DF, na gestão de Agnelo Queiroz, promulgou o decreto (Decreto no 34.517/2013) instituindo, no âmbito da Secretaria da Criança, o Centro de Atendimento Integrado a Crianças e Adolescentes Vítimas de Violência Sexual, como resultado do trabalho de concertação da rede de atenção e proteção, mas a efetiva implantação do CAI 18 de maio, ocorreu somente em dezembro de 2016, na Gestão de Rodrigo Rollemberg (GONÇALVES; MAGALHÃES; SANTOS, 2017).

Mesmo com a criação do Centro, sua implementação não foi efetiva, em decorrência de mudanças na gestão do governo local, inclusive na própria Secretaria da Criança, mas isso não desarticulou o GT, de modo que a sobrevivência da proposta foi mantida.

Somente em 2015, com a nova gestão do executivo local, o então Governador empossado, Rodrigo Rollemberg, do partido socialista brasileiro (PSB), implementou mudanças para que a proposta do Centro de Atendimento fosse adiante. Nesse sentido, poder-se-ia incorporar uma linha estratégica de Política de Enfrentamento à Violência de Crianças e Adolescentes. 
Definida a linha estratégica, faltava consolidar o espaço público para o atendimento às vítimas, o que veio a ser um antigo posto de policiamento de trânsito da Polícia Militar na Asa Sul, em Brasília, após as devidas reformas prediais para montagem da estrutura do local. O espaço foi finalmente inaugurado em outubro de 2016 e começou a funcionar efetivamente em dezembro do mesmo ano, após a equipe passar por um processo de capacitação para então iniciar os atendimentos (GONÇALVES; MAGALHÃES; SANTOS, 2017).

Estabelecido no centro da capital (Asa Sul quadra 307/8), o CAl 18 de maio, conforme designação, é um equipamento público de atendimento integrado e humanizado de crianças e adolescentes vítimas de violência sexual. Por ser único e centralizado, tem como objetivo contribuir para a atuação conjunta da rede, aproximando os processos de proteção e responsabilização de forma a evitar a revitimização do público atendido.

Para o seu funcionamento inicial, optou-se pela captação de recursos e parcerias públicas e privadas para instalação de brinquedoteca, aquisição de mobílias e equipamentos audiovisuais. Quanto ao corpo de profissionais atuantes no CAI 18 de maio, houve uma parceria na qual a Secretaria da Criança disponibiliza a maior parte de servidores para atuação no espaço - de 17 profissionais, 12 são mantidos por ela. A Secretaria de Saúde disponibiliza 2 profissionais, a Secretaria de Segurança Pública / Diretoria Geral da Polícia Civil, 2 agentes de Polícia e a Secretaria de Educação, 1 profissional. A Universidade de Brasília (UnB) disponibiliza 2 estagiários. As despesas de custeio ficam a cargo da Secretaria da Criança (GONÇALVES; MAGALHÃES; SANTOS, 2017).

Atualmente, até mesmo em função do entendimento da diferença entre escuta especializada e depoimento especial, os agentes da Segurança Pública já não estão no mesmo espaço. Por certo, ainda é prematuro avaliar se isso será fator relevante ou não para a celeridade e comprometimento do relato da vítima.

Quanto ao atendimento, o centro atende em turno integral de segunda a sextafeira, das $08 \mathrm{~h}$ às $20 \mathrm{~h}$, por demanda espontânea ou por encaminhamento de algum órgão da rede (disque 100 ou via Conselhos Tutelares). Segundo observação exploratória inicial, são atendidos em média cerca de 4 pessoas por dia, mas o Centro tem capacidade para atender até 6 pessoas. A maior demanda dá-se por meio dos Conselhos Tutelares, não, 
como se poderia pensar, através do Disque 100. Em Brasília, há cerca de 40 Conselhos Tutelares.

Tabela 1: Comparativo do número de denúncias do Disque 100

\begin{tabular}{cccc}
\hline \multicolumn{5}{c}{ Disque $\mathbf{1 0 0}$ - Ano 2017 - Comparativo } & 2016/2017, aumento do $\mathbf{n}^{\circ}$ denúncias por UF \\
\hline UF & $\mathbf{2 0 1 6}$ & $\mathbf{2 0 1 7}$ & \% de aumento \\
AP & 150 & 171 & $14,00 \%$ \\
CE & 3001 & 3970 & $32,29 \%$ \\
DF & 1908 & 1994 & $\mathbf{4 , 5 1 \%}$ \\
ES & 1294 & 1533 & $18,47 \%$ \\
GO & 2210 & 2523 & $14,16 \%$ \\
MA & 2023 & 2604 & $28,72 \%$ \\
\hline
\end{tabular}

Fonte: Disque 100 Adaptado de MDH (BRASIL, 2017).

Os dados acima apresentados demonstram um aumento significativo de denúncias contra crianças e adolescentes em 2017 pelo Ministério dos Direitos Humanos, órgão responsável pelo Disque 100 (considerando todo o Brasil), registraram uma violação de crianças e adolescentes a cada 6 minutos, proporcionando uma alta significativa de 7,2\% em relação a 2016. De certo, a denúncia não quer dizer efetivamente que houve o caso concreto de violação, mas é um prenúncio para apuração e prevenção.

Talvez para a grande maioria da população, o CAI 18 de maio é (in)visível, pois sua estrutura inicialmente não é perceptível e nem a sua localização, até mesmo os dados de sua existência são divulgados, quando são, precariamente. Segundo especialistas, isso foi proposital desde sua concepção, para se evitar a exposição e estigmatização ainda maior das crianças e adolescentes atendidos. Interessante observar que no local, seu espelhamento não permite saber o que há por trás dos vidros; ao se abrir a porta central, depara-se com a recepção e, logo ao lado, uma brinquedoteca, com mesinhas e cadeiras infantis, brinquedos, livros e jogos. O espaço também conta com espaço específico para adolescentes, denominado ateliê, que contém jogos, livros e um computador para games.

A sala de escuta especializada contém uma mesa infantil, um sofá, duas cadeiras, equipamentos de áudio e de vídeo e telefone; outra sala espelhada ao lado serve para assistir a entrevista por especialistas.

Então, o que seriam as boas práticas? Ainda que para muitos seja o mínimo proposto pelo Centro, é no atendimento que os profissionais da escuta procuram ambientar as vítimas e/ou testemunhas para a devida confiança dos relatos, sendo assim, 
a brinquedoteca, bem como o ateliê, corroboram para a interação entre o ouvinte e o comunicante, que posteriormente evidenciam o relatório psicossocial.

A metodologia de trabalho, idealizada inicialmente, procura dar o devido suporte com 3 profissionais simultaneamente para um mesmo atendimento: enquanto um deles faz a acolhida da família, na mesma sala a agente de polícia coleta as informações necessárias para a confecção do Boletim de Ocorrência. Concomitantemente, outra profissional inicia o rapport (diálogo em busca de uma ligação de sintonia e empatia) com a criança / adolescente na brinquedoteca ou no ateliê (GONÇALVES; MAGALHÃES; SANTOS, 2017).

As premissas de atendimento ocorrem com as seguintes etapas: (i) acolhimento; (ii) registro do Boletim de Ocorrência (BO); (iii) atendimento psicossocial; (iv) realização da escuta especializada, com filmagem e envio de mídia para abertura de inquérito; (v) devolutiva às famílias; (vi) acompanhamento das vítimas ao hospital e ao IML, quando necessário; (vii) produção de relatório psicossocial; (viii) contatos com a rede de proteção; (ix) encaminhamento para os serviços da rede; e (x) monitoramento sistemático junto às famílias (GONÇALVES; MAGALHÃES; SANTOS, 2017).

Todos os atendimentos conforme implementados pelo Centro geram um relatório psicossocial, que é enviado para a rede contendo dados como: identificação da vítima, histórico sociofamiliar e parecer.Os últimos dados de atendimento apresentados pelo Centro em relatório destacam que, de dezembro de 2016 a 9 de junho de 2017, o Centro totalizou 496 procedimentos: 73 escutas especializadas, 45 emissões de BO, 82 atendimentos psicossociais, 296 encaminhamentos para órgãos da rede de atenção e proteção e 105 relatórios psicossociais (este último com dados de até 7 de julho de 2017).

O relatório previsto para esse ano só deverá ser divulgado no final de 2018, mas que, preliminarmente, deverá manter o mesmo índice ou elevará o número de atendimentos (GONÇALVES; MAGALHÃES; SANTOS, 2017), segundo informações extraoficiais.

Portanto, o que pode-se, primeiramente, concluir é que o Centro de Atendimento 18 de maio é uma referência para Brasília, mesmo com toda a gama de dificuldades de integralização, pela ausência de profissionais especializados e falta de uma rede de dados. Precisou se considerar que fatores políticos, sociais e econômicos não podem ser fatores determinantes para novas implementações de outros centros, seja nas demais regiões 
administrativas (caso de Brasília), e em outras Unidades Federativas. O desafio está em considerar que a Lei deve ser cumprida e os profissionais valorizados com equipamentos e estrutura laboral condizente para que as boas práticas continuem pelo menos a amenizar a dor e o sofrimento, bem como identificar o abusador e, assim, possibilitar um novo recomeço às vítimas diante dos traumas.

\section{Considerações finais}

As boas práticas (espaço laboral composto por brinquedoteca e ateliê) a que se faz referência estão fundamentadas nos resultados alcançados em cada atendimento diário. O processo ocorre, ao promover (mesmo em meio à dor e ao sofrimento) a escuta num ambiente de acolhimento e de pertença, em espaços interativos de brincar. Logo, os desafios vão além dos números de atendimento, se considerar a demanda que tanto são apresentadas pelo Disque 100, quanto pelos Conselhos Tutelares.

O CAI 18 de maio procura alcançar as boas práticas por meio da primazia de bons profissionais, altamente especializados, não revitimizando a vítima diante do trauma vivido, mas o desafio permanece, especialmente em agregar novos profissionais envolvidos na formação e capacitação. Ainda há que se constatar que muitos profissionais já habilitados não são integrados por seus órgãos de origem para composição de novas equipes para atuarem em novos centros.

A manutenção de boas ações é importante para a efetivação das políticas públicas destinadas à condução de um atendimento de qualidade, que valorize a condição humana e não se comporte como causa de maior sofrimento para os sujeitos que procuram amparo nas instituições do Estado. Além disso, é notório que as articulações desenvolvidas tornam mais célere a proteção e a justiça. Um desafio associado a isso é a conscientização da sociedade civil e dos demais atores sociais no que tange à valorização do atendimento especializado.

O atendimento apresentado neste trabalho nos permite ter uma dimensão das possibilidades de atuação inclusiva no acompanhamento ou reincidências que o Estado pode assumir e que podem repercutir diretamente na vida das pessoas, de forma a garantir o princípio republicano da dignidade da pessoa humana. Indubitavelmente, é preciso integrar os sistemas para viabilizar a aferição do perfil das vítimas e dos supostos agressores e das famílias. 
Por fim, o desafio permanece latente em consolidar o Centro de Atendimento Integrado 18 de Maio como política intersetorial e protetiva, além das questões conjunturais que têm sido a troca de gestão nos órgãos institucionais, com o Conselho Tutelar e as direções das escolas. Assinala-se também que as práticas no Centro assumem um horizonte de valorização do cidadão e a preservação de seus direitos humanos, independentemente de suas condições sociais.

\section{Referências}

ALVES, C.; PEDROZA, R.; PINHO, A.; PRESOTTI, L.; SILVA, F. Adolescência e maioridade penal: reflexões a partir da Psicologia e do Direito. Psicologia Política, São Paulo, v. 9, n. 17, p. 67-83, jan./jun. 2009.

ARIÈS, P. História social da criança e da família. 2. ed. Rio de Janeiro: Zahar Editores, 1981.

BRASIL. [Constituição (1988)]. Constituição da República Federativa do Brasil de 1988. Brasília: Presidência da República, 1988. Disponível em: http://www.planalto.gov.br/ccivil_03/constituicao/constituicao.htm. Acesso em: 1 jul. 2018.

BRASIL. Lei no 13.431, de 4 de abril de 2017. Estabelece o sistema de garantia de direitos da criança e do adolescente vítima ou testemunha de violência e altera a Lei $n^{\circ} 8.069$, de 13 de julho de 1990 (Estatuto da Criança e do Adolescente). Brasília: Presidência da República, 2017. Disponível em: http://www.planalto.gov.br/ccivil_03/_ato20152018/2017/lei/L13431.htm. Acesso em: 10 jun. 2018.

BRASIL. Lei no 8.069, de 13 de julho de 1990. Dispõe sobre o Estatuto da Criança e do Adolescente e dá outras providências. Brasília: Presidência da República, 1990. Disponível em: http://www.planalto.gov.br/ccivil_03/leis/L8069.htm. Acesso em: 1 jul. 2018.

BRASIL. Ministério da Saúde. Secretaria de Vigilância em Saúde. Análise epidemiológica da violência sexual contra crianças e adolescentes no Brasil, 2011 a 2017. Boletim Epidemiológico, Brasília, v. 49, n. 27, jun. 2018.

COLLOR, F. Crianças, o desafio maior: discursos presidenciais. Brasília: Presidência da República, 1990. Disponível em: http://www.biblioteca.presidencia.gov.br/publicacoesoficiais/catalogo/collor/criancas-o-desafio-maior-1990-discurso-2. Acesso em: 1 jul. 2018.

FONSECA NETO, A. C.; PAULA, M. V.; BORGES, N. M. M. Infância socialmente vulnerável e corpo. In: PINHEIRO, M. C. M. (org.). Intensidade da infância: corpo arte e o brincar. Goiânia: FUNAPE, 2010. p. 139-155.

FOUCAULT, M. Vigiar e punir: o nascimento da prisão. Petrópolis: Vozes, 2013.

FURNISS, T. Abuso sexual da criança: uma abordagem multidisciplinar. Porto Alegre: Artes Médicas, 1993. 
GARANHANI, M. C.; NADOLNY, L. F. O movimento do corpo infantil: uma linguagem da criança. In: UNIVERSIDADE ESTADUAL PAULISTA; UNIVERSIDADE VIRTUAL DO ESTADO DE SÃO PAULO (org.). Caderno de formação: formação de professores: educação infantil: princípios e fundamentos. São Paulo: Cultura Acadêmica, 2011. p. 65-74. (Coleção Caderno de Formação, v. 3).

GHIRALDELLI JR., P. As concepções de infância e as teorias educacionais modernas e contemporâneas. Educação e Realidade, Porto Alegre, v. 25, n. 1, p. 45-58, jan./jun. 2000.

GONÇALVES, I. B.; MAGALHÃES, D. R.; SANTOS, B. R. (ed.). Centros de atendimento integrado a crianças e adolescentes vítimas de violências: boas práticas e recomendações para uma política pública de Estado. São Paulo: Instituto WCF, 2017.

IBGE - INSTITUTO BRASILEIRO DE GEOGRAFIA E ESTATÍSTICA. Brasília: censo. Rio de Janeiro: IBGE, 2010. Disponível em:

https://cidades.ibge.gov.br/brasil/df/brasilia/pesquisa/23/25888?detalhes=true. Acesso em: 1 jul. 2018.

BRASIL. Ministério da Mulher, da Família e dos Direitos Humanos. Balanço Disque 100 2017. 2017. Disponível em: https://www.mdh.gov.br/informacao-aocidadao/ouvidoria/dados-disque-100/balanco-geral-2011-a-2017.xlsx/view. Acesso em: 1 jul. 2018.

MEDEIROS, Diego Vale de. O papel da defensoria pública no atendimento extrajudicial e judicial às crianças e aos adolescentes em situações de violência sexual. In. Escuta de crianças e adolescentes em situação de violência sexual: aspectos teóricos e metodológicos: guia para capacitação em depoimento especial de crianças e adolescentes / organizadores, Benedito Rodrigues dos Santos, Itamar Batista Gonçalves, Gorete Vasconcelos ; (coords.), Paola Barbieri, Vanessa Nascimento - Brasília, DF : EdUCB, 2014.

MINAYO, M. C. S. Pesquisa social: teoria, método e criatividade. Petrópolis: Vozes, 2010.

OLIVEIRA, M. M. Como fazer pesquisa qualitativa. Petrópolis: Vozes, 2013.

ONU - ORGANIZAÇÃO DAS NAÇÕES UNIDAS. 16o objetivo: paz, justiça e instituições eficazes. Brasília: ONU, 2015. Disponível em: https://nacoesunidas.org/pos2015/ods16/. Acesso em: 1 jul. 2018.

PAPALIA, D. E.; FELDMAN, R. D. Desenvolvimento humano. 12. ed. Porto Alegre: AMGH, 2013.

ROMARO, R. A.; CAPITÃO, C. G. As faces da violência: aproximações, pesquisas, reflexões. São Paulo: Vetor, 2007.

SILVA, C. F. A socioeducação e direitos humanos: um estudo do projeto "A Arte do Saber". 2017. 172 f. Dissertação (Mestrado em Direitos Humanos e Cidadania) - Universidade de Brasília, Brasília, 2017. 
SINAN - SISTEMA DE INFORMAÇÃO DE AGRAVOS DE NOTIFICAÇÃO. O Sinan. Brasília:

Sinan, 2019. Disponível em: http://portalsinan.saude.gov.br/. Acesso em: 10 ago. 2019.

Recebido em: 02/12/2018

Aceito em: 11/11/2019 